\title{
The Numerical Simulation for Heat-transfer process of Photovoltaic Rolled Glass in Forming Stage
}

\author{
GENG Tie ${ }^{1, a}$, LIU Dan-dan ${ }^{1, b}$, TU Wei-qing ${ }^{1, c}$ \\ ${ }^{1}$ Collage of Mechanical \& Electrical Engineering, Henan University of Technology, Zhengzhou \\ 450007, China \\ a tiegeng2000@163.com, bliudan5251@126.com, ' $1301236948 @ q q . c o m$
}

Keywords: photovoltaic rolled glass; formative stages; fluid flow and heat transfer; numerical simulation

\begin{abstract}
The calculation model on analysis convective heat transfer established is according to the structural features of photovoltaic rolling glass in its forming stage. The computational fluid dynamics (CFD) software FLUENT was used for numerical simulation of flow field; The study analysis the temperature variation of the region in different working conditions, which will verify the feasibility of the numerical simulation; The conclusion can provide reference for the design and optimization of calender forming process.
\end{abstract}

\section{Introduction}

From recent literatures it is noticed that there is a great potential development and broad prospects of photovoltaic rolled glass ${ }^{[1-2]}$. Since 2007 super white rolled glass began to be produced in China, we have already had 45 production lines ${ }^{[3]}$ and a producing ability of $5950 \mathrm{t} / \mathrm{d}$. The producing ability of Ultra-white original film is 18600 ten thousand square meters and the actual production is 9296.9 ten thousand square meters.

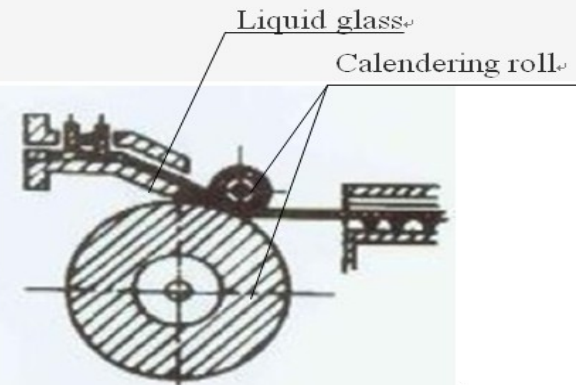

Fig. 1 Continuous calendaring

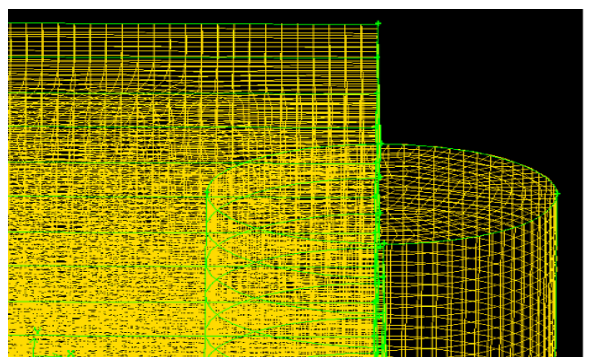

Fig. 2 Local grid model for water-cooled roller

Solar photovoltaic rolled glass is a kind of figured glass that almost produced by rolling process. The glass forming after raw materials are melted in high temperature condition and flow into the rolling mill (Fig.1). In the forming, cooling rate of calender rolls is too rapid that will result in the temperature of products unequally distributed. The temperature is too high that will result in sticky die and the deformation of product ${ }^{[4]}$, therefore, in the conditions of guarantying clear embossing and not mucosa, it's the key to study that ensuring the temperature of roller surface, and carefully choosing rod diameter, wall thickness, stick materials as well as the adjustment of quantity of cooling water. The article uses CFD software to analysis the heat transfer of forming process and explores molding theory, thus providing the persuasive convenient way for the actual production.

\section{Molding and numerical calculation}

\section{Geometric model and meshing}

In the forming process, the study of heat transfer is based on the water-cooled roller heat transfer of calendars roll as the main research object; Therefore, the article is based on a simplified water-cooled roll model of an enterprise that has a length of $2600 \mathrm{~mm}$ and outside diameter of $260 \mathrm{~mm}$ and the diameter of the cooling water channel $160 \mathrm{~mm}$. The pre-treatment software GAMBIT in FLUENT of commercial CFD software is used to construct the three-dimensional solid 
model and meshing for the study area. Using structured hexahedron mesh (Fig.2), the number of volume gird and surface grid is 22010 and 73147, through using GAMBIT and FLUENT to inspect the grid skew degree and volume, the gird shewness of more than 0.4 is less than $3 \%$ and the minimum volume is greater than zero, so the mesh precision meet the requirements.

\section{Mathematical model and numerical solution method}

Generally, in the area under consideration, the fluid flow and heat transfer should meet the quality, momentum and energy conservation equation. This study applies the standard k- $\varepsilon$ turbulence model and wall function method to analog the liquidity situation of computational domain; The SIMPLEC algorithm used to solve pressure and velocity coupling and the momentum and turbulence parameters solved by using First-Order Upwind format. The above equation can be summarized to a unified equation form, i.e. ${ }^{[5-6]}$ :

$$
\operatorname{div}(\rho \vec{V} \phi)=\operatorname{div}(\operatorname{\Gamma grad} \phi)+S
$$

The standard k- $\varepsilon$ turbulence equation:

$$
\begin{aligned}
& \rho \frac{\partial k}{\partial t}=\rho\left(\frac{\partial k}{\partial t}+u_{j} \frac{\partial k}{\partial x_{j}}\right)=\frac{\partial}{\partial x_{j}}\left[\left(\mu+\frac{\mu_{t}}{\sigma_{k}}\right) \frac{\partial k}{\partial x_{j}}\right]+G-\rho_{\varepsilon} \\
& \rho \frac{\partial \varepsilon}{\partial t}=\rho\left(\frac{\partial \varepsilon}{\partial t}+u_{j} \frac{\partial \varepsilon}{\partial x_{j}}\right)=\frac{\partial}{\partial x_{j}}\left[\left(\mu+\frac{\mu_{t}}{\sigma_{\varepsilon}}\right) \frac{\partial \varepsilon}{\partial x_{j}}\right]+\frac{c_{1} \varepsilon}{k} G-c_{2} \rho \frac{\varepsilon^{2}}{k}
\end{aligned}
$$

Listed above where: $\mathrm{k}$ is the turbulent kinetic energy, $\varepsilon$ is the dissipation rate of turbulent kinetic energy, $\sigma_{k} \backslash \sigma_{e}$ are the Prandtl numbers that corresponding to the kinetic turbulent energy $\mathrm{k}$ and the dissipation rate $\varepsilon$, $\mathrm{G}$ is the produce item which is caused by the average speed of turbulent kinetic energy $\mathrm{k}, \mathrm{c} 1=1.44$, c2 $=1.92$, are the empirical constants.

\section{Boundary conditions}

Both outer and inner surfaces of the water-cooled roller are wall, the outer surface that contacts with the liquid glass which needs to be applied the temperature of liquid flows into the roller, and the temperature is $1400^{\circ} \mathrm{C}$; The inner surface that contacts with the cooling water is the wall of liquid - solid coupled heat transfer, the temperature of cooling water as the default value; The roller speed is $150 \mathrm{~m} / \mathrm{h}$; The cooling water flow rate of the inlet boundary was given two different speeds of $0.1 \mathrm{~m} / \mathrm{s}$ and $0.5 \mathrm{~m} / \mathrm{s}$; The export of the cooling water is outflow, and the rest of the area using the default boundary.

\section{Results and analysis}

The $y=0$ cross-section is shown in the figure 3 and figure 4 is the face which perpendicular to the $\mathrm{x}$-axis and divide the water-cooled rollers into two same volumes. The two graphics respectively have two graphics, each of them mean the temperature contour changes under the two cases of $t=5$ $\min$ and $\mathrm{t}=10 \mathrm{~min}$.

For the flow and heat transfer of forming process, the roller speed, the access speed of cooling water and the length of cooling time, etc. are likely to the process conditions that be good or bad affect the heat transfer. The simulation results show that:(1) In the same situation of inlet cooling water flux into speed, the longer time of pass into, the better effect of heat transfer.(2)The faster speed of cooling-water flux into, the more quality of heat will be take away. These are consistent with the production experience.

The wall-1 and wall-2 are shown in Fig.5 and Fig.6 respectively represent the outer and inner surfaces of the water-cooled roller (coupling wall).It can be seen from Fig.3-8 that the temperature distribution of the outer surface of the roller are inconsistent after passing into the cooling water. Just passing into cooling water, although the water temperature is the lowest, the effect of roller heat transfer is very poor. The entrance temperature of wall- 1 is the highest and substantially in the given temperature of liquid glass. After a short time, the temperature of wall-1 falls sharply and then tends to be stable state. Shown in Fig.5 and Fig.6, the degree of temperature drop relate to the initial 
flux into speed of cooling water. Since the wall-2 is contact with the water surface, the temperature change is less obvious. After a period of time of passing into cooling water, the temperature of the wall is slightly rising (Fig.7), which indicate that the quantity of heat of the roller took away by the water flowing process lead to the temperature of cooling water rise, thus, the convection heat transfer coefficient of coupling surface is relatively decline (as shown in Tab.1). However, as shown in figure 8, this phenomenon basically cannot be seen after continuous to access the cooling water. The temperature of roller can meet the requirements of calendaring temperature except the temperature of entrance is higher.

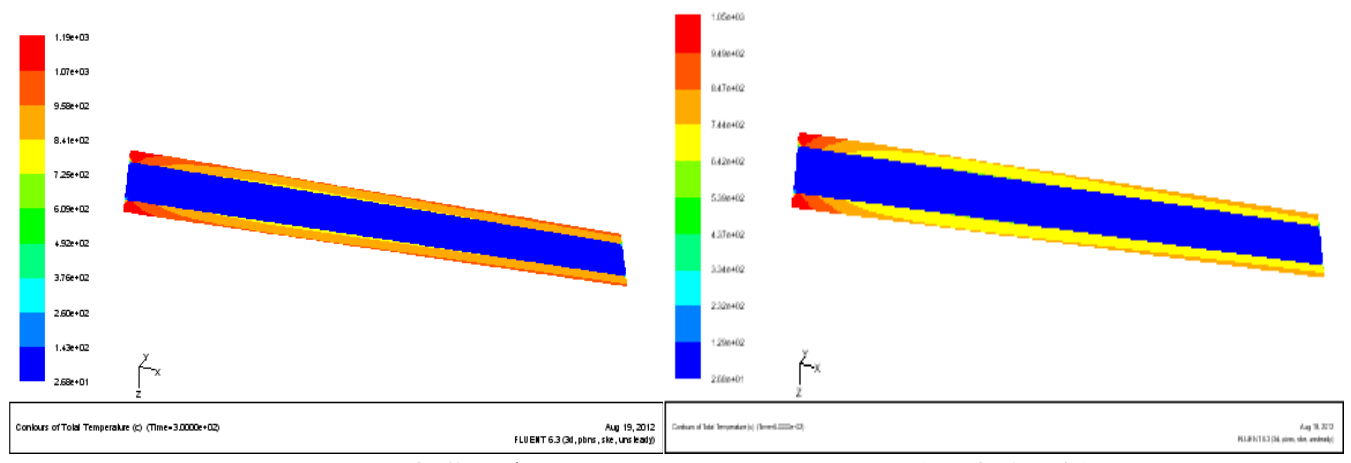

Fig. $3 \mathrm{y}=0$ Section temperature contour $(\mathrm{v}=0.1 \mathrm{~m} / \mathrm{s})$



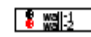

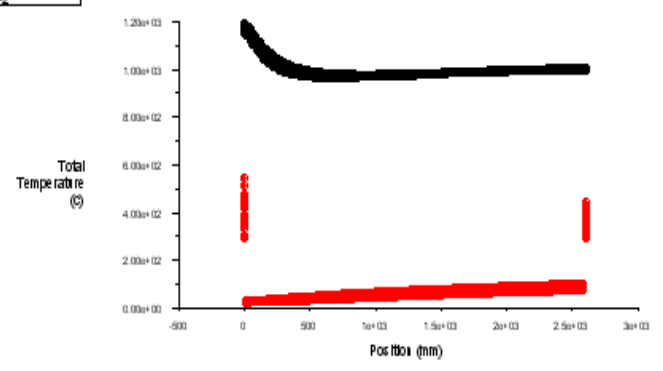

Fig. 5 XY-Plot temperature curve $(\mathrm{v}=0.1 \mathrm{~m} / \mathrm{s})$

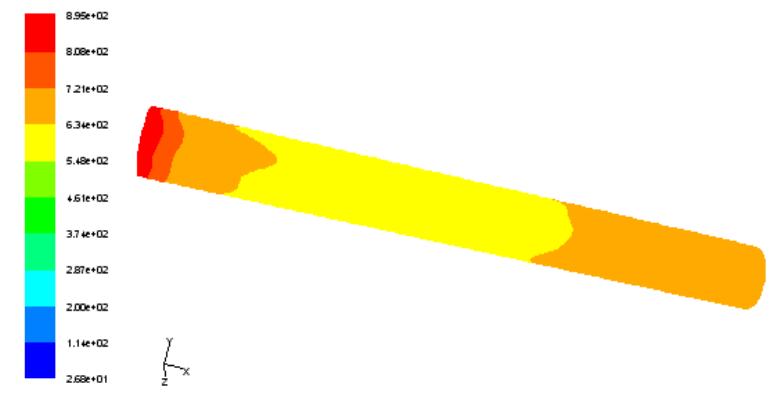

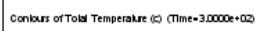

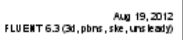

Fig. 7 Outer surface temperature distribution of water-cooled roller $(\mathrm{v}=0.5 \mathrm{~m} / \mathrm{s}, \mathrm{t}=5 \mathrm{~min})$
( $=0.5 \mathrm{~m} / \mathrm{s})$
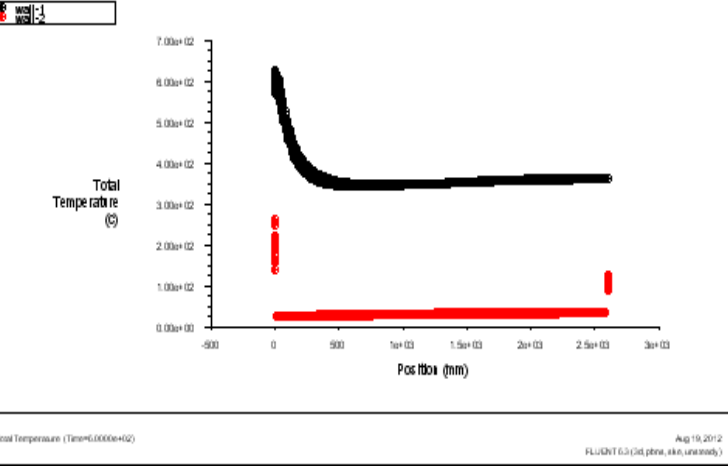

Fig. 6 XY-Plot temperature curve $(v=0.5 \mathrm{~m} / \mathrm{s})$

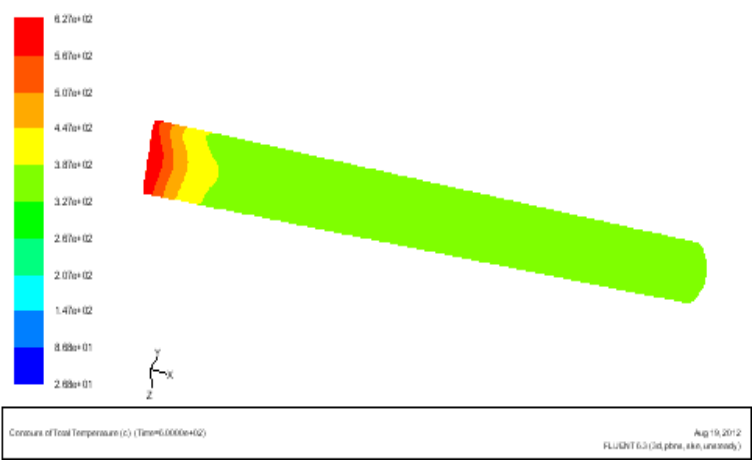

Fig. 8 Outer surface temperature distribution of water-cooled roller $(\mathrm{v}=0.5 \mathrm{~m} / \mathrm{s}, \mathrm{t}=10 \mathrm{~min})$ 
Tab.1 shows the temperature of two different conditions and the heat transfer coefficient of wall-1 and wall -2 .

Tab.1 The chart of simulation results

\begin{tabular}{|c|c|c|c|}
\hline Inlet velocity [s] & Time[s] & $\begin{array}{c}\text { The temperature of } \\
\text { Wall- }\left[\left[{ }^{\circ} \mathrm{C}\right]\right.\end{array}$ & $\begin{array}{c}\text { The heat transfer coef. of Wall-2 } \\
{\left[\mathrm{w} / \mathrm{m}^{2} . \mathrm{k}\right]}\end{array}$ \\
\hline \multirow{2}{*}{0.1} & 300 & $1073.96-1190.31$ & 274.87 \\
\cline { 2 - 4 } & 600 & $846.63-1051.57$ & 273.49 \\
\hline \multirow{2}{*}{0.5} & 300 & $721.19-894.78$ & 1465.42 \\
\cline { 2 - 4 } & 600 & $386.67-626.54$ & 1389.36 \\
\hline
\end{tabular}

\section{Conclusion and prospect}

1) Application of CFD method as a research tool can specific describe the flow and heat transfer condition of flow field as well as provide help for the study and optimization of rolled glass forming.The results of simulation show that the heat transfer of the cooling water roller is closely related to the flux time of cooling water. The bad situation of heat transfer in inlet section can be improved by increasing the drainage segment.

2) In this study, the simplified model has a gap with the actual situation, the results of simulation contrast with experience at least be feasible. In the future, the research should focus on making the model close to the actual forming that to make the more rigorous analysis, so as to explore more accurate forming rules to guide practice.

\section{References}

[1] Hao Xiang-guo, Xu Mei-jun. The development and market of rolled glass. Glass industry Annual Conference and Technical Symposium Proceedings. (2009) 66-819.

[2] Huang Hua-yi, Li Xiao-dong. The Application and Prospect of the ultra-white embossed with the transparent conductive film glass in the industry of solar cell. Architectural glass and industrial glass.168 (3) (2009) $21-25$.

[3] Liu Zhi-hai. The development and consumer analysis of China's ultra-white glass. China Building Materials. (2011) 57 -61.

[4] Yin Hai-rong, Li Qi-jia. The forming and precision machining of glass. Chemical Industry Press.p.111-116(2010).

[5] Tao Wen-shuan. Numerical heat transfer. Xi'an: Xi'an Jiaotong University Press (1995).

[6] Han Tao, Liu Zong-ming, Zhang Tie-zhu. Study of numerical simulation based on CFD used for Fiberglass Furnace.Glass fiber.5: (2010) 1-8. 